\title{
The recent state of cryopreservation techniques for ex-situ gene conservation and breeding purposes in small ruminants: A review
}

\author{
Malam Abulbashar Mujitaba ${ }^{1}$ - Nóra Vass ${ }^{1}$ - Szilárd Bodó ${ }^{2}$ \\ ${ }^{1}$ University of Debrecen, Doctoral School of Animal Science, Böszörményi street, 138, 4032, Debrecen, Hungary. \\ ${ }^{2}$ National Agricultural Research and Innovation Center, Gödöllö, Hungary. \\ malam.abulbashar@agr.unideb.hu
}

\begin{abstract}
SUMMARY
The viewpoint of the recent cryopreservation techniques (CT) suggests the use of a reduced volume of cryopreservation solution, high concentration of cryoprotectants and ultra-rapid cooling and warming rates help to reduce cryo-injury and maximize the viability of the preserved animal genetic resources (AnGR). The CT had now become widely accepted as one of the best methods of choice for the ex-situ conservation of AnGR due to its high success rate recorded and no-invasive nature as compared to the conventional slow rate freezing (CSRF). Rapid advances and wide acceptability of the use of assisted reproductive technologies (ART's) particularly artificial insemination (AI) in animal breeding had resulted in a greater loss of a large number of good quality genes in virtually almost all the native breeds of animals across the globe. Small ruminant (SR) animals are not an exception in such present predicaments situation of erosion and dilution of the valuable AnGR among the native breeds. As a result of this, 148 and 16 breeds of sheep and goats respectively have already become extinct in Europe and the Caucasus. In view of the aforementioned situation, the present review aimed at exploring some of the current states of development, roles played and potentials of CT in the conservation of SR genes and genome for the immediate and future breeding purposes for sustainable development. It basically covers; animal genetic resource, the need to conserve AnGR, tools for ex situ in vitro conservation of AnGR and recent developments in breeding and cryopreservation of SR AnGR.

Cryopreservation is playing a pivotal role in ex-situ gene conservation of AnGR. Decline in genetic diversity among SR breed population was high in Europe and the Caucasus. There is therefore, need for improvent on current stringent measures on conservation of AnGR in this region of the world.
\end{abstract}

Keywords: Small ruminants, Cryopreservation, Ex-situ gene conservation, Animal Genetic Resource and Breeding

\section{INTRODUCTION}

Cryopreservation involves the freezing of gametes, embryos, gonadal tissues, or somatic tissues of species (Silva et al., 2015). The cryopreservation techniques (CT) is an imperative tool that gives a lead way for the successful application of the latest advances in the present biotechnologies like cloning, transgenesis and long - term storage/conservation of animal genetic resource (AnGR) (Panyaboriban et al., 2018). It was observed that, the loss of AnGR across the globe is occuring at shocking rate. According to FAO (2007) at least a breed of livestock is becoming extinct at each month over some years ago, resulting in the loss of its genetic charcteristics forever. In Europe and the Caucasus alone 148 and 16 breeds of sheep and goats respectively have already become extinct. Furthermore, Europe and the Caucasus, and North America are the two areas in the world with the highest proportion of atrisk breeds. In absolute terms, the highest number of atrisk breeds can be found in Europe and the Caucasus (FAO, 2007; 2015). Hence, there is therefore, an urgent need for conservation of small ruminant (SR) AnGR as they are faced with a continual decline or threaten by extinction. A number of ways/methods are available for conserving animal biodiversity, among which include; in vivo, ex situ in vivo and ex situ in vitro conservation (Gibson et al., 2006). These methods of conservation are complementary, with dynamic interactions among them. But with the current rates of change in economic development and in agriculture production systems that are expected in most of the developing world, in situ conservation is unlikely to be sufficient to conserve most AnGR. Other approaches to conservation will clearly be required. For instance, in the case of severe and rapid threat to AnGR that has substantial current value, in vitro conservation in cryo-bank may be the safest and best option (Gibson et al., 2006). Similarly, Silva et al. (2015) reported that one of the most convenient and less costly alternative for conservation of AnGR of endangered species is "Germplasm cryoservation" which is the ex situ in vitro conservation. Ex situ in vitro conservation refers to conservation external to the living animal in an artificial environment, under cryogenic conditions which include; the cryoconservation of embryos, semen, oocytes, somatic cells or tissues having the potential to reconstitute live animals at a later date (FAO, 2007).

Gene banks are considered to be the key and most dynamic instrument for ex situ conservation of AnGR (Paiva et al., 2014). Genome resource banking is the systematic collection, storage, and re-distribution of biomaterials in an organized, logistical, and secure manner (Agca, 2012). The ability to acquire samples cryopreserved in the past facilitates a gene bank's acquisition of additional genetic diversity (Blackburn, 2012). Gene banks have a lot of advantages in animal production, the most notable among them include; acquiring germplasm/tissue, enhance the genetic variability for in situ populations of several rare breeds; provide breeders of larger breeds with genetic variability to use in their breeding programs, and for molecular genetics and reproductive physiology research (Blackburn, 2012). In consequence of these, 
there has been an increase in the number of ex situ conservation programs involving both in vivo and in vitro preservation (Silva et al., 2015). Paiva et al. (2014), reported a Global estimate of established national gene banks with accumulated substantial inventories of germplasm and tissues in 50 countries which are dispersed across all geographic regions. Since the early 2000's the minimum size of the global collection likely exceeds 34,000 animals and over 3,300,000 germplasm/tissue samples across species excluding the stores for sale at AI companies.

The aim of this review was to explore some of the recent development, potentials and roles played by CT in conservation of SR genes and genome for the immediate and future breeding purposes for sustainable development.

\section{ANIMAL GENETIC RESOURCE}

Animal genetic resources are defined as genetic diversity in domesticated animal species having economic or other socio-cultural values and found among species, within species, among animal breeds, and in cryoconserved material (embryos and semen). Genetic diversity refers to differences in allele frequencies and allele combinations among breeds of farm animal species and the spectrum of genetic variation within the breeds (Kantanen et al., 2015). The history of AnGR started around 12000 to 14000 years ago, during the agricultural revolution of the early Neolithic, with the domestication of major crop and livestock species. This control of food production led to major demographic, technological, political and military changes (FAO, 2007). The pressure of selection imposed by climate, soil type, altitude, available feed supply, endemic diseases and parasites, variability in management techniques and market demands have resulted in the immergence of many breeds, types and strains, each having a specific genetic make-up and adapted to a particular environmental niche. Such selection process will continue in the future and is the source of the diversity of AnGR we have at present (Balcha, 2004).

\section{THE NEED TO CONSERVE ANIMAL GENETIC RESOURCE}

The AnGR diversity contributes in many ways to human survival, well-being and vital to all production systems; as it provides the raw material for breed improvement, and for adaptation to changing circumstances (Drucker, 2004; FAO, 2007). Galal (2005) reported that $12.7 \%$ of sheep and $13.6 \%$ of goat breeds in the world are at risk of becoming extinct, while $12.8 \%$ of sheep and $3.1 \%$ of goat have already become extinct. According to the Report of Second State of the World's AnGR's for Food and Agriculture, the regions with the highest proportion of their breeds classified as at-risk are Europe and the Caucasus (31\% of mammalian breeds and $35 \%$ of avian breeds) and North America (16\% of mammalian breeds). Sheep and cattle has the highest number of at risk and extinct breed in the world with cattle having 184 breeds and sheep having a total of 160 extinct breed (FAO, 2015). Such an irreversible loss of genetic diversity reduces opportunities to improve food security, reduce poverty and shift towards sustainable agricultural practices. On the other hand, to the livestock keeper the loss of the local breed appears to be economically rational because returns may simply be higher than that from activities compatible with genetic resources conservation. Therefore, livestock keeper preferences for different traits, are critical inputs for designing breeding and conservation strategies (Drucker, 2004.) There is therefore, a need for conservation of AnGR. From Table 1 it implies that total proportion of world population of SR for Europe and the Caucasus is declining, although, the recent report indicated an increased in the number of local breeds in both sheep and goats. This probably, suggest that more local breeds were identified or some of the extinct breeds were reconstituted.

Table 1

Comparison of the status and trend of small ruminants AnGR of Europe and the Caucasus based on reports by First and Second state of the World's Animal Genetic Resources for Food and Agriculture

\begin{tabular}{|c|c|c|c|c|}
\hline \multirow[b]{3}{*}{ Parameters } & \multicolumn{4}{|c|}{ Species } \\
\hline & \multirow{2}{*}{$\frac{\text { Sheep }}{\text { FSoW-AnGR }}$} & \multicolumn{3}{|c|}{ Goats } \\
\hline & & SSoW-AnGR & FSoW-AnGR & SSoW-AnGR \\
\hline $\begin{array}{l}\text { Countries reporting breed-related } \\
\text { information }(\%)\end{array}$ & 100 & - & 93 & - \\
\hline Proportion of world population (\%) & 18 & 14 & 4 & 3 \\
\hline Proportion of world breed (\%) & 48 & - & 3 & - \\
\hline Local breed & 458 & 613 & 170 & 218 \\
\hline Regional transboundry breeds & 79 & 74 & 13 & 14 \\
\hline Extincnt breeds & 148 & 145 & 16 & 16 \\
\hline
\end{tabular}

FSoW-AnGR: First State of the World's Animal Genetic Resources for Food and Agriculture

SSoW-AnGR: Second State of the World's Animal Genetic Resources for Food and Agriculture

Source: FAO (2007; 2015). 
Gibson et al. (2006), reported that AnGR are faced by a number threats which vary substantially across breeds and regions. These threat are categorized into five groups in descending order based on their impact/severity and their time scale. Furthrmore, a suitable combination of conservation strategies for a given AnGR is based on the severity and speed of the threats the AnGR is exposed to, the nature of the value of the AnGR and the capacity for action. Table 2 shows the five threat group to AnGR and their possible conservation approaches.

Five threat group to AnGR and their conservation approaches

\begin{tabular}{|c|c|c|}
\hline Groups & Threat & Conservation approaches \\
\hline I & Epidemic disease, war and civil conflict HIV/AIDS & In vitro and ex situ in vivo \\
\hline II & Instability (political \& economic) and urbanization & Ex situ in vivo \\
\hline III & $\begin{array}{l}\text { Cross-breeding, lack of policies, lack of political will, intensification/changing } \\
\text { production systems, lack of valuation of local breeds, trade agreements and market } \\
\text { preferences. }\end{array}$ & $\begin{array}{l}\text { In situ, complemented with in vitro } \\
\text { for endangered populations }\end{array}$ \\
\hline IV & $\begin{array}{l}\text { Increasing competition for natural resources, environmental degradation/Pollution and } \\
\text { natural disasters }\end{array}$ & Ex situ in vivo \\
\hline $\mathrm{V}$ & Climate change and endemic diseases & In situ \\
\hline
\end{tabular}

NB: Severity and speed of the threats decrease with the number of group.

Source: Gibson et al. (2006).

An attempt to adress the problem of the loss of AnGR led to gene banks establishement in different countries to preserve genetic diversity and integrity for the benefits of current and future generations. However national programmes are quite different in terms of stakeholder involvement and institutional framework (Hiemstra, 2019). In many cases CT is restricted to the storage of semen from a limited number of breeds. A few countries have gene banks preserving semen of all main species. There is therefore, need for further development (FAO, 2007). Table 3 shows some of the established gene banks in some selected coutries in Europe.

Some established gene banks in some selected coutries in Europe

\begin{tabular}{|c|c|c|c|c|c|}
\hline Name of gene banks & Country & Samples & Species & Breeds & Source \\
\hline Center for Genetic Resources, The Netherlands (CGN) & Albania & NA & 10 & 136 & $(\mathrm{CGN}, 2019)$ \\
\hline AREC Raumberg- umpenstein & Austria & 252485 & 4 & 26 & (Eugena, 2019) \\
\hline BNGA & Spain & 72982 & 5 & 48 & (Eugena, 2019) \\
\hline UMo, BTF & Montenegro & 523 & 3 & 7 & (Eugena, 2019) \\
\hline CGN & Netherlands & 470462 & 10 & 135 & (Eugena, 2019) \\
\hline Rare Breeds Gene Bank & New Zealand & NA & 11 & 124 & (Rare-Breeds, 2019) \\
\hline PE LVC "Velika Plana" & Serbia & 280 & 1 & 1 & (Eugena, 2019) \\
\hline CBVB Krnjaca & Serbia & 600 & 1 & 4 & (Eugena, 2019) \\
\hline Temerin & Serbia & 700 & 1 & 3 & (Eugena, 2019) \\
\hline
\end{tabular}

NA: No data Available

The magnitude of cost savings plus the elimination of depressed levels of performance for in situ populations suggest a critical need for greater gene banking efforts. According to the First State of the World's AnGR report (FAO, 2007) most in vitro conservation programmes in Europe are found in the Western and Central part of the region. Further attempt to adress the problem of loss of AnGR was made in Europe, which is National Strategies and Action Plans implementing the Global Plan of Action for AnGR. National action plans include development and implementation of cryopreservation strategies for AnGR. Although some cross-border collaboration exists in Europe, cryopreservation programmes are national responsibilities and generally organised at the national level (Hiemstra, 2019). Gibson et al. (2006) reported that single conservation method is rarely suitable, and in most cases two or more methods are complementary to each other and a detailed analysis is required for each AnGR, leading to a coherent strategy for conservation that will include an appropriate combination of in situ and/or ex situ in vivo and/or in vitro conservation methods.

\section{TOOLS FOR EX SITU IN VITRO CONSERVATION OF ANIMAL GENETIC RESOURCE}

\section{Gamete cryoconservation}

Semen CT have been the most widely used method for germplasm preservation of endangered species, due 
to its convenience and ease of application (SouzaFabjan, 2011; Kasai, 2002). The technique has makes it possible to freeze sperm cells thereby, arresting all it metabolic activities and can be remobilized at later time from the frozen state (Faigl et al., 2012). Buck semen cryopreservation and thawing protocols are very similar to that of ram. Semen can be cryopreserved either by the pellet technique (i.e. on the surface of solid carbon dioxide) or in straws $\left(0.25 \mathrm{ml}, 1 \times 10^{8}\right.$ spermatozoa) that are held in the vapor phase of liquid nitrogen (LN2) or cooled down in programmable cell freezers (Faigl et al., 2012). Most commonly used diluents for cryopreservation of ram semen are two Tris-based diluents: Tris-glucose-egg yolk and Triscitrate-fructose-egg yolk. For goat semen, they contain either egg yolk or dried skim milk, both can be detrimental to the goat sperm cells (Salamon and Maxwell, 2000; Evans and Maxwell, 1987; Gangwar et al., 2016). This aspect was thoroughly reviewed by Faigl et al. (2012).

Current oocyte CT are derived from embryos and sperm, with some modification, this development will virtually enhance long-term conservation of their female AnGR and the advancement of SR embryonic biotechnology (Quan et al., 2017). It is considered as the best way to preserve the genetic material of postmortem females (Souza-Fabjan et al., 2011). Ideally, oocytes will be frozen along with semen from the breed to be conserved, as otherwise backcrossing with semen from another breed will be needed to reconstitute an extinct population. Techniques for freezing and thawing oocytes are less well developed and refined than those for semen and embryos, and require further field evaluation (FAO, 2012). Moreover, with oocyte cryopreservation, through in vitro fertilization (IVF) desired matings can be selected at the time of thawing, rather than at the time of freezing (FAO, 2007). Unfortunately, sheep oocyte cryopreservation are rare and much less frequent than those of the other domestic animals, such as bovine or porcine (FAO, 2007). This was presumed to be due to high content of cytoplasmic lipid droplets in sheep oocytes coupled with complex subcellular structures which affect their relatively higher sensitivity of the oocytes to chilling and freezing stresses (Quan et al., 2017). According to the current reports, the blastocyst formation efficiency of cryopreserved sheep oocytes remains low after in vitro fertilization and generally less than $10 \%$, the highest blastocyst rate reported was 17\% (Succu et al., 2008). Delipidation was considered as a promising technique in improving vitrified oocyte/embryo viability. It can be achieved by media supplementation using; fatty acids, carnitine, phenazine ethosulfate, forskolin or mechanically (Braga et al., 2019). Delipidation resulted in the reduction in lipid contents, high blastocyst and survival rate in oocytes/embryo after vitrification and thawing in sheep (Romão et al., 2015), porcine (Gajda et al., 2011), bovine and buffalo (Panyaboriban et al., 2018).

\section{Selection of the best quality gamete for cryopreservation}

The use of epididymal sperm cells in ART on endangered animals could be considered a useful source. According to the sperm maturation process, sperm from the cauda epididymis are of good quality and potentially fertile (Souza-Fabjan et al., 2011). These spermatozoa can also be used for IVF procedures even after freezing and thawing. Thus spermatozoa can be collected even from slaughtered male animals if there is no other possibility available (Brem, 1989). Sperm live/dead ratio can be easily and rapidly assessed by using Kovács-Foote staining procedure (Kovács and Foote, 1992). Another approach for semen quality assessment is by the use of combination of several seminal quality attributes (Garner and Johnson, 1997). Similarly, Chenoweth (2002) reported that choosing semen should reflect different aspects of sperm function (morphology and motility). Morphology or differential count of normal and abnormal cells, the minimum recommended threshold for sperm morphology should be atleast 70\% (Chenoweth, 2002). For motility, the semen samples are assessed for gross and individual motility with a minimum recommended threshold of fair "generalized oscillation and 30-49\%" for the gross and individual motility respectively as shown in Table 4.

Table 4

Mass and individual motility of sperm

\begin{tabular}{lcl}
\hline \multicolumn{1}{c}{ Motility } & Individual & \multicolumn{1}{c}{ Rating } \\
Mass Motility & 70 & Very good \\
\hline Rapid swirling & $50-60$ & Good \\
Slower swirling & $30-49$ & Fair \\
Generalized oscillation & $<30$ & Poor \\
Sporadic oscillation & & \\
\hline
\end{tabular}

Source: Chenoweth (2002).

It is essential to assess the fertility potentials and guarantee the necessary health qualities of the oocytes since the developmental competence of an embryo is principally dictated by the oocyte (Hoshino, 2018). Usually, for in vitro fertilization (IVF) and intracytoplasmic sperm injection (ICSI), oocyte selection is based on morphological parameters related to the cumulus cells, polar body, and cytoplasm (Hoshino, 2018; Wani et al., 2013). Wani et al. (2013) Graded oocytes into three categories based on the number of cumulus cells and uniformity of the oocytoplasm, these are;

i. Good: Oocytes with many complete layers of cumulus cells and uniform cytoplasm.

ii. Pair: Oocytes with thin or incomplete layers of cumulus cells and uniform cytoplasm.

iii. Poor: Oocytes with few or no cumulus cells.

To achieve good result, only good and pair oocytes should be used.

Potentially, oocyte quality can be assess by using intracellular temperature imaging with the help of 
fluorescent polymer thermometer (FPT) to evaluate the thermal profile of the oocytes. It can also be determined by assessing molecular markers (microRNAs) and certain morphological factors that are related to oocytes quality like; first polar body morphology, meiotic spindle, cumulus cells and mitochondria (Hoshino, 2018).

\section{Embryo cryoconservation}

After successful production/recovery of the embryos from the donor animals, sometimes, the total number of the embryos are usually higher than the number required for the ET program, hence, there is need to preserve the supernumerary embryos (Banker et al., 2017). As a result, investment in research was increased to develop an efficient protocol for the preservation of the remaining embryos. This brought about the idea of embryo CT (Sanches et al., 2017). For breed reconstitution, embryos have an advantage over semen, in that they allow the recovery of the entire genome (i.e. no backcrossing is required) and thus the reconstitution can be accomplished in a single generation (FAO, 2012). Embryo cryopreservation can be achieved by either conventional slow rate freezing (CSRF) or vitrification technique (VT) defending on the specie of animal involved. Numerous years ago, VT allowed good results for in vitro produced (IVP) embryos because of its simplicity, speed, high viability due to zero ice crystal formations and low cost (Sanches et al., 2017). The major problem of this technique is the toxicity of the solution due to high concentration of cryoprotectant used to prevent the formation of extracellular ice (Sanches et al., 2017). Luckily, embryos have a multicellular structure, even if some cells in embryos are damaged after cryopreservation, the remaining healthy cells still can proliferate to replace those damaged cells (Quan et al., 2017). A lot of improvements have been brought to book regarding improvement of CT. It is now possible to cryopreserve many types of embryos with a minimal loss of viability, although more delicate handling of embryos is required than with the CSRF (Kasai and Mukaida, 2004).

Selection of best quality embryos for cryopreservation Embryos, can be assessed for quality according to their morphological aspect due the time after insemination and the integrity of the pellucid membrane that surround the embryo (Rizos et al., 2002). Geber et al. (2002) identified the following criteria for assessing embryo quality;

i. Developmental rate: embryos must be assessed in culture, during the 1-cell, cleaving and morula/blastocyst stages, and classified according to quality. At day 2, the first cleavage division occurs. After this, embryos double their number of blastomeres each day. Thus embryos have an expected $2-4$ cells at day $2,6-10$ cells on day 3 , become morula at day 4 and blastocysts at day 5 and 6. Embryos with odd numbers of blastomeres probably have cells with slower division than others in human beings. ii. Morphology: best embryos are those having thinner zonae and blastomeres of similar size without fragments. Thicker zonae might impair hatching while greater degrees of fragmentation and blastomere irregularity give a poor prognosis of pregnancy.

Combination of all these criteria in order to select the most likely embryos to implant might improve pregnancy rates.

\section{Cells and tissue cryoconservation}

The technologies for cryopreservation of different cells and tissues are at varying levels of development, cost and ease of application for different species (Gibson et al., 2006). Collection of tissues other than germ cells and embryos can be useful for gene banking, either for the production of new animals through somatic cell nuclear transfer (SCNT) or to obtain genetic and health-related information about the animals sampled (DNA isolated from cells) (FAO, 2012). It may be a prudent backup in circumstances where cryoconservation of gametes and embryos is not financially or technically feasible or has very low success rates. In its most simple application, banking somatic cells requires only the collection and direct freezing of a piece of tissue, samples can be obtained from section taken from the ear, skin, hair or blood (FAO, 2012). The storage of slices of ovaries in LN2 could also be a possible way for cryopreservation of genomes. Future prospects for CT may benefit from the banking of somatic cells on the other hand requires breakthroughs in cryopreservation and generation of offspring from cryopreserved; Parts of ovaries, embryonic stem cells (ESC), spermatogonial cells, primordial germ cells or through parthenogenetic embryo production (FAO, 2007). Nevertheless, as countries continue to develop collections, there is an opportunity to ensure that future collection activities accommodate the primary objective of conservation and security as well as to incorporate new types of tissues and areas of collection use; for example, ovaries for transplantation or skin or fibroblast tissues for either DNA extraction or cloning (Paiva, 2014). Table 5 shows the current status of CT in SR.

Current status of cryopreservation techniques in small ruminants

\begin{tabular}{ccccc}
\hline & \multicolumn{4}{c}{ Samples } \\
\cline { 2 - 5 } Species & Semen & Oocyte & Embryos & Somatic cells \\
\hline Sheep & + & O* & + & O \\
Goat & + & O & + & O \\
\hline
\end{tabular}

+Routine technique available; $\mathrm{O}$ : Positive Research Result; *Cryopreservation of whole ovary. Source: (FAO, 2007)

\section{RECENT DEVELOPMENTS IN BREEDING AND CRYOPRESERVATION OF SMALL RUMINANT ANIMAL GENETIC RESOURCES}

Small ruminant breeding has witness yet another interesting milestone in sheep breeding which is the 
Juvenile In vitro Embryo Transfer (JIVET). With this technique, it is now possible to produce a live lamb from a female sheep that is as young as six to eight weeks of age. In South Australia, Stud White Suffolk sheep producers have bred what is believed to be the first lamb of its kind in the world. What makes this lamb to be unique; it was born from a frozen embryo. The oocytes were collected, fertilized in vitro, frozen, thawed after storage and transferred to recipient ewes. Six to eight weeks of age are used because this is the peak period for egg production in sheep (Hough, 2018). The real benefits of this technology is that, by the time the lamb that donated those eggs is six-months-old, she actually got progeny on the ground. At 12 month, she's a grandmother and has two crops of progeny and by 18 months, when she would have her first lamb naturally, she's a great grandmother with potentially hundreds of progeny or descendants on ground (Hough, 2018). So the technique shorten generation interval than the conventional breeding system of ET.

Another interesting development is "modified vitrification methods" an approach which aimed to overcome the problem of high chilling injury experienced in cryopreserved occytes and embryo of certain species. In this method, cooling and warming rate is markedly increased by minimizing the volume of the solution. The modified methods use electron microscope grids, open-pulled straws, cryoloops, or container-less microdrops (Kasai, 2002). Recently, new storage media, including LN2 slush or liquid helium, have been used to increase the cooling/warming velocity (Quan et al., 2017). Moreover, with recent advances in RNA sequencing technology, it is possible to systematically analyze the transcriptome in oocytes. The transcriptome can represent the complete gene expression pattern of oocytes at a specific developmental stage or after specific treatments. Meanwhile, the differentially expressed genes can function as necessary biomarkers to assess the postthaw quality of oocytes to optimize the current CT of sheep oocytes and embryos (Quan et al., 2017).

\section{CONCLUSION}

This review revealed that, cryopreservation of SR semen and embryos has become routine practice for $e x$ situ gene conservation purposes. There are positive research results on oocytes and ovarian tissue cryopreservation. The technique allows for maintaining viability of the cryopreserved AnGR for an indefinite period, this has lead an appreciable success that warrants the establishment of gene banks across many countries. On the other hand, vitrified in vitro produced sheep oocytes and embryos still showed a greater sensitivity to freeze-thawing characterized by low viability. There is therefore, a need to conduct more research on the subject to improve their freeze-thawing resistance, developmental competence and viability. In addition, decline in the genetic diversity among SR breed populations was noticed. Europe and the Caucasus regions were reported to have the highest number of at-risk breeds. An urgent improvement on the current stringent measures and concerted efforts on promoting conservation of AnGR is needed to save SR biodiversity for future breeding purposes.

\section{REFERENCES}

Agca, Y. (2012): Genome Resource Banking of Biomedically Important Laboratory Animals. Theriogenology. 78. 1653-1665.

Balcha, G. (2004): Keynote Address In: ESAP (Ethiopian Society of Animal Production). Farm Animal Biodiversity in Ethiopia: Status and Prospects. Asfaw Yimegnuhal and Tamrat Degefa (Eds). Proceedings of the $11^{\text {th }}$ Annual conference of the Ethiopian Society of Animal Production (ESAP) held in Addis Ababa, Ethiopia, August 28-30, 2003. ESAP, Addis Ababa. 441.

Banker, M.-Kotdawala, A.-Gupta, R. (2017): The Impact of Vitrification in Artificial Reproductive Technology Programmes. European Medical Journal. 2. 82-89.

Blackburn, H. D. (2012): Animal Genetic Resource Information FAO. Retrieved $10 \quad 23, \quad 2019$, from http://www.fao.org/3/i3017e/i3017e00.pdf.

Braga, J. V.-Komninou, E. R.-Vieira, A. D.-Mondadorie, R. G. (2019): Approaches to reduce lipids: a review of its impacts on in vitro embryo production. Revista Brasileira de Reprodução Animal. 1. 3-7.

CGN (2019): Gene Bank Data. Retrieved from Centre for Genetic Resources, the Netherlands: www.genebankdata.cgn.wur.nl/cgibin/uk/breed2.php

Chenoweth, P. J. (2002 ): Semen Quality Assessment. The Applied Reproductive Strategies in Beef Cattle Workshop, Manhattan, Kansas. 247-255.
Drucker, A. G. (2004): Economics of AnGR conservation and sustainable use: Theory, practice and implications. In: Yimegnuhal, A.-Degefa, T. (eds). Farm animal biodiversity in Ethiopia: Status and prospects. Proceedings of the $11^{\text {th }}$ Annual conference of the Ethiopian Society of Animal Production (ESAP) held in Addis Ababa, Ethiopia, 28-30 August 2003. Addis Ababa, Ethiopia: ESAP. 441.

EUGENA (2019): Gene Banks. Retrieved from the European Genebank Network for Animal Genetic Resources: https://eugena-erfp.net/en/.

Evans, G.-Maxwell, W. M. (1987): Salamon's Artificial Insemination of Sheep and Goats. Sydney, Australia.: Butterworths.

Faigl, V.-Vass, N.-Jávor, A.-Kulcsár, M.-Solti, L.-Amiridis, G.Cseh, S. (2012): Artificial insemination of small ruminants - A review. Acta Veterinaria Hungarica, 60. 115-129.

FAO (2007): The State of the World's Animal Genetic Resources for Food and Agriculture, edited by Barbara Rischkowsky and Dafydd Pilling. Rome.

FAO (2010): Cryoconservation of Animal Genetic Resource. FAO. Retrieved $10 \quad 23, \quad 2019$, from http://www.fao.org/3/i3017e/i3017e02.pdf.

FAO (2012): Section 8 collection of germplasm and tissues. In: cryoconservation of animal genetic resources, animal production and health guideline. Retrieved from: 
http://www.fao.org/3/i3017e/i3017e00.pdf. on December 1, 2019.

FAO (2015): The Second Report on the State of the World's Animal Genetic Resources for Food and Agriculture, edited by Scherf, B. D. and Pilling, D. FAO Commission on Genetic Resources for Food and Agriculture Assessments. Rome (available at http://www.fao.org/3/a-i4787e/index.html).

Gajda, B.-Romek, M.-Grad, I.-Krzysztofowicz, E.-Bryla, M.Smorag, Z. (2011): Lipid content and cryotolerance of porcine embryos cultured with phenazine ethosulfate. Cryo-Letters. 32 . 349-357.

Galal, S. (2005): Biodiversity in Goats. Small Ruminant Research. 60. 75-81.

Gangwar, C.-Kharche, S. D.-Kumar, S.-Jindal, S. K. (2016): Cryopreservation of Goat Semen: Status and Prospects. Indian Journal of Small Ruminants. 22. 1-10.

Garner, D. L.-Johnson, L. A. (1995): Viability assessment of mammalian sperm using SYBR14 and propidium iodide. Biology of Reproduction. 53. 276-284.

Geber, S.-Sales, L.-Sampaioa, M. A. (2002): Laboratory techniques for human embryos. Reproductive Bio Medicine Online. 5. 2: 211-218.

Gibson, J.-Gamage, S.-Hanotte, O.-Iñiguez, L.-Maillard, J. C.Rischkowsky, B.-Semambo, D.-Toll, J. (2006): Options and Strategies for the Conservation of Farm Animal Genetic Resources: Report of an International Workshop (7-10 November 2005, Montpellier, France). CGIAR System-wide Genetic Resources Programme (SGRP)/ Bioversity International, Rome, Italy. 53.

Hiemstra, S. J. (2019): Cryopreservation Strategies for Farm Animal Genetic Resources in Europe. Retrieved from https://edepot.wur.nl/217691.

Hoshino, Y. (2018): Updating the markers for oocyte quality evaluation: intracellular temperature as a new index. Reproductive Medicine and Biology. 17. 434-441.

Hough, C. (2018): Lamb born in South Australia using frozen in-vitro embryo transfer. Retrieved 11 01, 2019, from ABC NEWS: https://www.abc.net.au/news/rural/2018-09-01/world-firstfrozen-jivet-lamb-born/10183892.

Kasai, M. (2002): Adva in the cryopreservation of mammalian oocytes and embryos: Development of ultrarapid vitrification. Reproductive Medicine and Biology. 1. 1-9.

Kasai, M.-Mukaida, T. (2004). Cryopreservation of Animal and Human Embryos by Vitrification. Reproductive BioMedicine Online. 9. 164-170.

Kantanen, J.-Løvendahl, P.-Strandberg, E.-Eythorsdottir, E.-Li, M. H.-Kettunen-Præbel, A.-Berg, P.-Meuwissen, T. (2015): Utilization of farm animal genetic resources in a changing agroecological environment in the Nordic countries. Frontiers in Genetics. 6: 1-9. doi:https://doi.org/10.3389/fgene.2015.00052.

Kovács, A.-Foote, R. H. (1992): Viability and acrosome staining of bull, boar and rabbit spermatozoa. Biotechnic and Histochemistry. $67 . \quad 3$ : 119-124. https://doi.org/10.3109/10520299209110020
Paiva, S. R.-McManus, C.-Blackburn, H. (2014): Conservation of Animal Genetic Resources: the Next Decade. Proceedings, $10^{\text {th }}$ World Congress of Genetics Applied to Livestock Production.

Panyaboriban, S.-Tharasanita, T.-Chankitisakulc, V.-SwangchanUthaia, T.-Techakumphua M. (2018): Treatment with chemical delipidation Forskolin prior to cryopreservation improves the survival rate of swamp Buffalo (Bubalus bubalis) and bovine (Bos indicus) in vitro embryo. Criobiology. 84. 46-51.

Quan, G.-Wu, G.-Hong, Q. (2017): Oocyte Cryopreservation Based in Sheep: The Current Status and Future Perspective. Biopreservation and Banking, 15. 535-547.

Rare-Breeds (2019): Rare and Minority Breeds of Livestock in New Zealand. Retrieved from Gene Bank Rare Breeds Conservation Society of New Zealand: https://www.rarebreeds.co.nz/list.html.

Rizos, D.-Lonergan, P.-Ward, F.-Duffy, P.-Boland, M. P. (2002): Consequences of bovine oocyte maturation, fertilization or early embryo development in vitro versus in vivo: implications for blastocyst yield and blastocyst quality. Molecular Reproduction and Development. 61. 234-248.

Romão, R.-Marques, C. C.-Baptista, M. C.-Barbas, J. P.-Horta, A. E.-Carolino, N.-Bettencourt, E.-Pereira, R. M. (2015): Cryopreservation of in-vitro-produced sheep embryos: Effects of different protocols of lipid reduction. Theriogenology. 84. 1: $118-126$.

Salamon, S.-Maxwell, M. C. (2000): Storage of ram semen. Animal Reproductive Science. 62. 77-111.

Sanches, B. V.-Zangirolamo, A. F.-Covre da Silva, N.-Morotti, F.Seneda, M. M. (2017): Cryopreservation of in vitro-produced embryos: challenges for commercial implementation. Proceedings of the $31^{\text {st }}$ Annual Meeting of the Brazilian Embryo Technology society (SBTE), (pp. 521-527). Brazil. doi: 10.21451/1984-3143-AR995.

Silva, A. R.-Lima, G. L.-Peixoto, X. G.-Souza, A. L. (2015): Cryopreservation in mammalian conservation biology: current applications and potential utility; A Review. Research and Reports in Biodiversity Studies. 4. 1-8.

Souza-Fabjan, J. M.-Batista, R. I.-Melo, L. M.-Freitas, V. J. (2011): Reproductive biotechnologies applied to the conservation of endangered ruminant - past, present and future. Revistaportugues a de ciências veterinárias. 110. 577-580.

Succu, S.-Bebbere, D.-Bogliolo, L.-Ariu, F.-Fois, S.-Leoni, G. G.Berliguer, F.-Naitana, S.-Ledda, S. (2008): Vitrification of in vitro matured ovine oocytes affects in vitro pre-implantation development and mRNA abundance. Molecular Reproduction and Development. 75: 538-546.

Wani, A. R.-Khan, M. Z.-Sofi, K. A.-Malik, A. A.-Lone, F. A.Bhat, F. A. (2013): Effect of Folliclar Size on In vitro Maturation, Fertilization and Culture of Sheep Embryos. Iranian Journal of Veterinary Research, Shiraz University, 14. 
